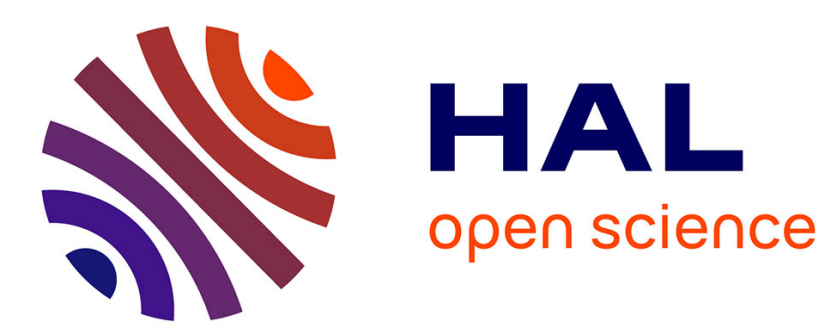

\title{
Enantioselective Synthesis of Atropisomers with Multiple Stereogenic Axes
}

\author{
Xiaoze Bao, Jean Rodriguez, Damien Bonne
}

\section{To cite this version:}

Xiaoze Bao, Jean Rodriguez, Damien Bonne. Enantioselective Synthesis of Atropisomers with Multiple Stereogenic Axes. Angewandte Chemie International Edition, 2020, 59 (31), pp.12623-12634. 10.1002/anie.202002518. hal-02905416

\section{HAL Id: hal-02905416 https://hal.science/hal-02905416}

Submitted on 23 Jul 2020

HAL is a multi-disciplinary open access archive for the deposit and dissemination of scientific research documents, whether they are published or not. The documents may come from teaching and research institutions in France or abroad, or from public or private research centers.
L'archive ouverte pluridisciplinaire HAL, est destinée au dépôt et à la diffusion de documents scientifiques de niveau recherche, publiés ou non, émanant des établissements d'enseignement et de recherche français ou étrangers, des laboratoires publics ou privés. 


\section{Enantioselective Synthesis of Atropisomers with Multiple Stereogenic Axes}

Xiaoze Bao,* Jean Rodriguez, and Damien Bonne*

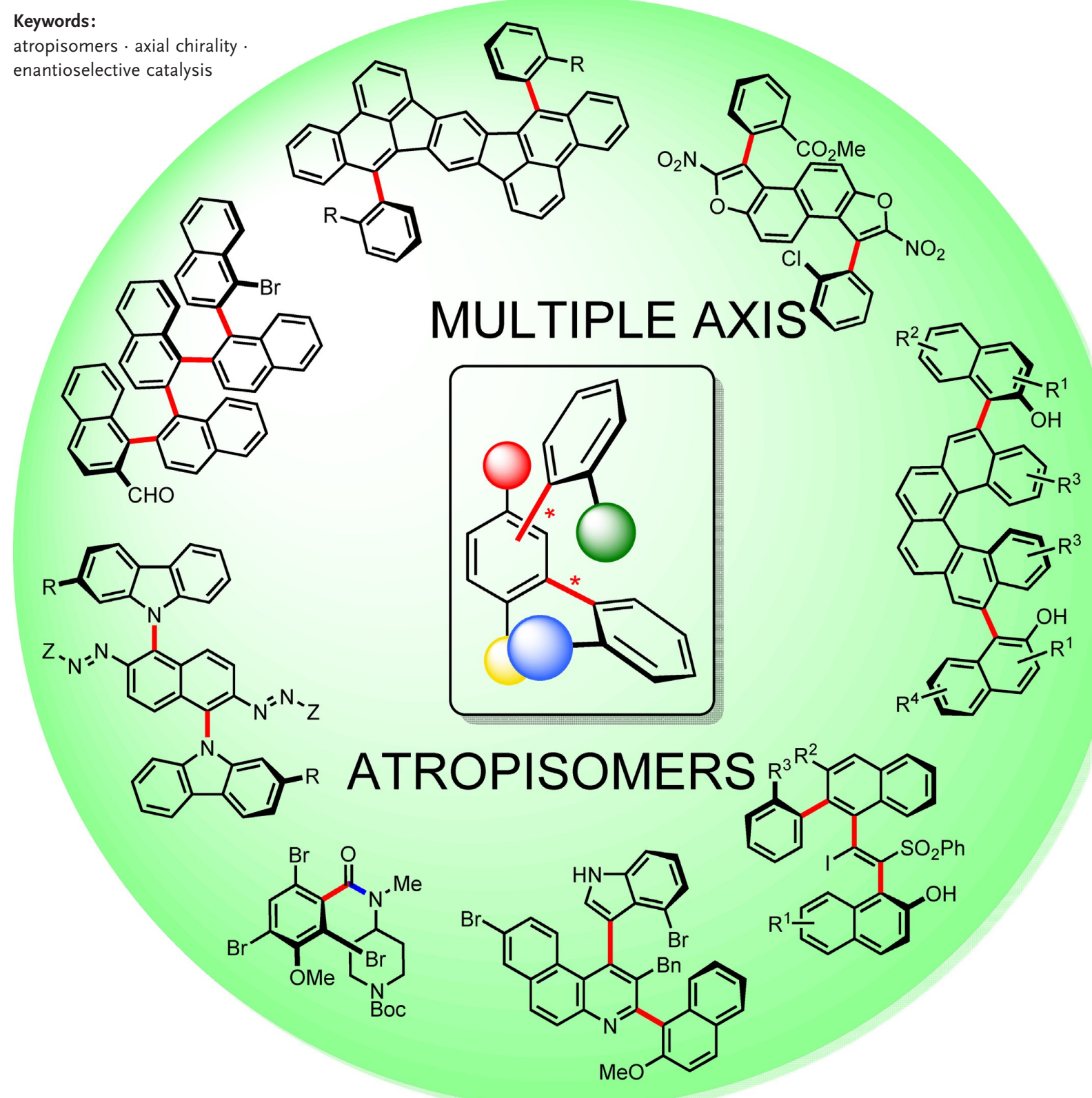


A tropisomers possessing multiple stereogenic axes are intriguing molecules with huge potential. However, only few approaches for their enantioselective synthesis are available due to the difficulties in assembling various stereogenic axes with high enantiocontrol. Only recently, innovative methods have emerged, opening new possibilities for the synthesis of this original class of atropisomeric compounds. This Minireview describes the development of this field based on a classification of the multi-axis systems according to the distance between the stereogenic axes and the strategy used to build them.

Nevertheless, the stereodivergency in accessing these molecules remains a daunting challenge, which has been addressed only three times, by control of either the substrate or the catalyst (see Schemes 14, 17, and 23). This Minireview will cover the development of this field, based on a classification of the multi-axis systems into five types (Scheme 2a, types A-E) according to the distance between the stereogenic axes.

To direct enantioselective access to these attractive systems, the five fol-

\section{Introduction}

Atropisomers are a subclass of conformers arising from restricted rotation around a single sigma bond, which can be isolated as separate enantiomers when the barrier to rotation is high enough. ${ }^{[1]}$ Nonracemic atropisomers are widely represented in natural products, ${ }^{[2]}$ and they also find numerous applications, for example, in chiral catalysts ${ }^{[3]}$ and functional materials. ${ }^{[4]}$ Over the past few decades, the enantioselective synthesis of atropisomers has attracted the attention of synthetic chemists, and great efforts have been made to construct atropisomers featuring one stereogenic axis. ${ }^{[5]}$

On the other hand, implementing functional molecules with multiple stereogenic axes leads to intriguing and more complex topologies that may have unique applications in material science and catalysis. ${ }^{[6]}$ Nature has proved its ability to build atroposelectively molecular systems; numerous complex natural products with multiple stereogenic axes exist and have important biological activities (Scheme 1, axes in red)..$^{[2,7]}$ The pharmaceutical industry is also exploring several atropisomeric drug candidates with multiple stereogenic axes, such as BMS-986141, a reversible inhibitor of Bruton's tyrosine kinase. ${ }^{[8]}$ This recent interest further drives the development in this area. However, compared to the huge efforts dedicated to the enantioselective preparation of molecules with multiple stereogenic $\mathrm{C}\left(\mathrm{sp}^{3}\right)$ centers, the methods for the catalytic enantioselective construction of molecules with multiple stereogenic axes are rather limited. ${ }^{\left[{ }^{[9]}\right.}$ Following the seminal work of Hayashi in 1989 on the synthesis of double-axis systems, ${ }^{[10]}$ the last three decades have witnessed growth in this field, especially in recent years.
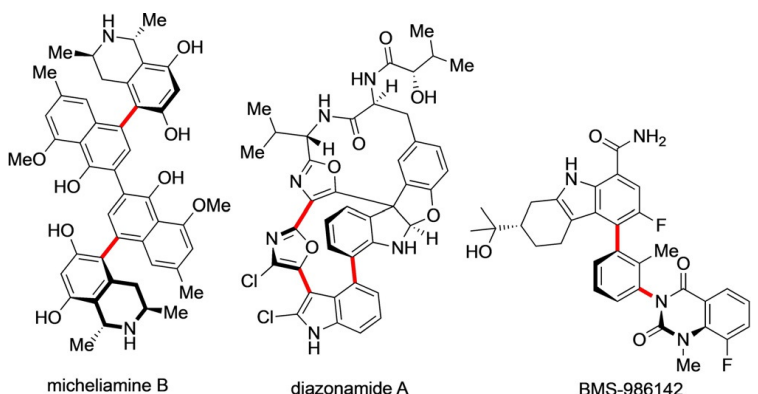

micheliamine B lowing strategies have been developed to date (Scheme 2b): 1) aryl-aryl cross-coupling, 2) $(2+2+2)$ cycloaddition, 3) dynamic kinetic resolution, 4) central-to-axial chirality conversion, and 5) trapping chiral vinylidene-quinone methides (VQMs). These five elegant and complementary strategies will be described in detail in the next section.

\section{Strategies for the Construction of Multiple-Axis Systems}

\subsection{Aryl-Aryl Cross-Coupling (Type D Molecules)}

The enantioselective cross-coupling of aryl partners under transition-metal catalysis is one of the most important transformations for the preparation of axially chiral biaryls with one stereogenic axis. ${ }^{[2 b, 11]}$ Interestingly, the first example of enantioselective synthesis of atropisomers with two stereogenic axes through enantioselective cross-coupling was reported by Hayashi and co-workers in 1989 (Scheme $3 a){ }^{[10]}$ The synthesis of the chiral 1,4-diaxial ternaphthalenes $(R, R)-\mathbf{4}$ and $(R, R)-\mathbf{5}$ was accomplished with the nickel- $(S)$ $(R)$-PPFOMe complex $\left(\mathrm{NiBr}_{2} / \mathbf{L 1}\right)$, which catalyzed a highly enantioselective double Kumada cross-coupling between the Grignard reagent $\mathbf{1}$ and the corresponding dibromonaphthalenes $\mathbf{2}$ and $\mathbf{3}$. The stereochemical outcome of the double coupling was consistent with the stereoselectivity in the crosscoupling of Grignard reagent $\mathbf{1}$ and 1-bromonaphthalene (6) (Scheme 3b). Based on the enantioselectivity of $(R)-7$ $(80 \% e e)$ and the Horeau chiral amplification principle, ${ }^{[12]}$ $(R, R)-\mathbf{5}$ could be isolated with a theoretical diastereo- and

[*] Dr. X. Bao

College of Pharmaceutical Science \& Collaborative Innovation Center of Yangtze River Delta Region Green Pharmaceuticals Zhejiang University of Technology Hangzhou 310014 (China) E-mail: baoxiaoze2008@aliyun.com Prof. Dr. J. Rodriguez, Dr. D. Bonne Aix Marseille Université, CNRS Centrale Marseille, iSm2 Marseille (France) E-mail: damien.bonne@univ-amu.fr

Scheme 1. Natural products with multiple stereogenic axes. 


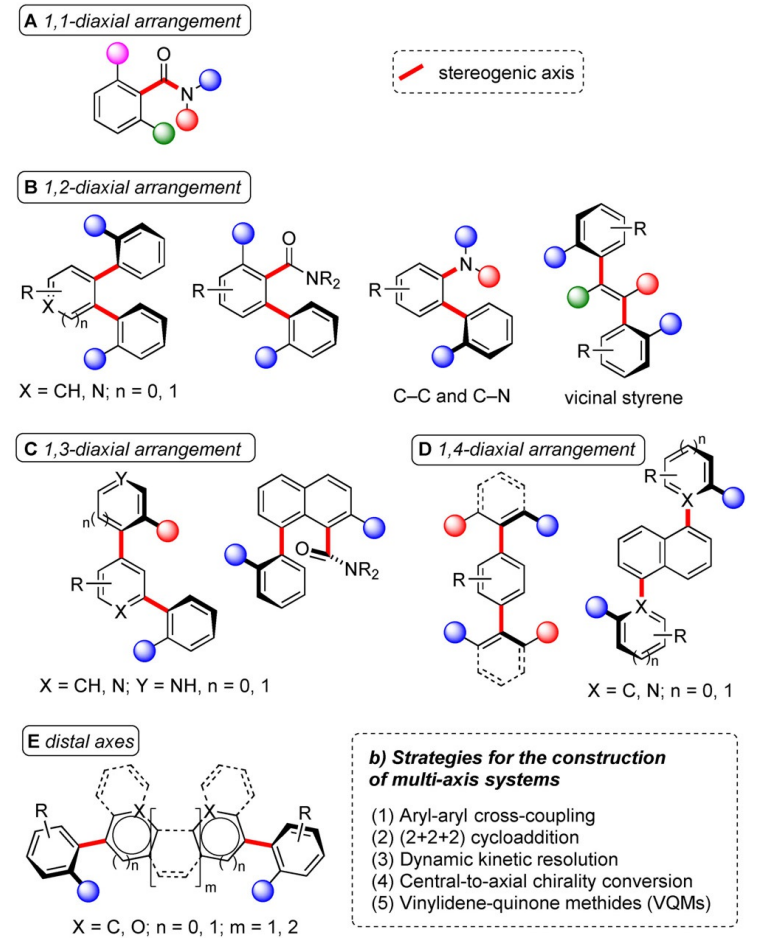

Scheme 2. Types of multi-axis systems and strategies for their construction.<smiles>Brc1cccc2c(Br)cccc12</smiles>

b)

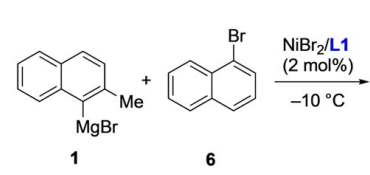

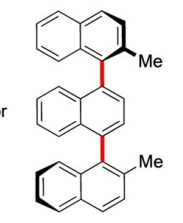

$(R, R)-5$
$d r=86: 14$ $\begin{array}{cc}d r=84: 16 & d r=86: 14 \\ \% \text { yield, } 98.7 \% \text { ee } & 74 \% \text { yield, } 95.3 \%\end{array}$

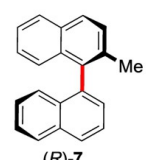

(R)-7

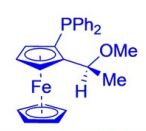

L1: (S)-(R)-PPFOMe

Scheme 3. Enantioselective synthesis of axially chiral ternaphthalenes.

enantioselectivity of $64 \%$ and $97.6 \%$, respectively. This was in good agreement with the experimental observation of $(R, R)-5$ isolated with $86: 14 d r$ and $95.3 \%$ ee. These results indicated the advantages of the Horeau chiral amplification principle in the construction of atropisomers with two or multiple axes in high enantiomeric excesses.

In 2019, Shi and co-workers described the first highly enantioselective N-heterocyclic carbene (NHC)-Pd-catalyzed Suzuki-Miyaura cross-coupling reaction for the synthesis of

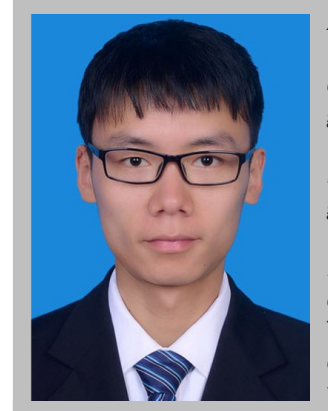

Xiaoze Bao was born in Zhejiang Province (China) in 1991. He received his bachelor's degree (2012) and PhD (2017) under the guidance of Professor Baomin Wang at Dalian University of Technology. In 2018, he conducted postdoctoral research in the group of Dr. D. Bonne and Prof. Dr. J. Rodriguez at Aix Marseille Université. In 2019, he returned to China and became an associate professor at Zhejiang University of Technology. His research focuses on the development of new enantioselective synthetic methodologies.

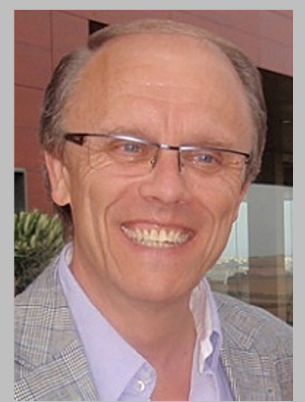

Jean Rodriguez was born in Cieza (Spain) in 1958 and in 1959 his family emigrated to France. After studying chemistry at the University of Aix-Marseille (France), he completed his PhD as a CNRS researcher with Prof. B. Waegell and Prof. P. Brun in 1987. After a postdoctoral position with Prof. K. P. C. Vollhardt at the University of California, Berkeley (USA) in 1988, he completed his Habilitation in 1992, also at Marseille, where he is currently Professor and Director of the UMR-CNRS-7313. iSm2. His research interests include the development of multiple bond-forming transformations including domino and multicomponent reactions, and their application in stereoselective organocatalyzed synthesis.

Damien Bonne was born in Epinal (France)
in 1979. After studying chemistry at the
Ecole Supérieure de Chimie de Lyon (CPE
Lyon, France), he completed his PhD in
2006 under the supervision of Prof. J. Zhu
working on isocyanide-based multicompo-
nent reactions. He then moved to the
University of Bristol (UK) to join the group
of Prof. V. A. Aggarwal as a postdoctoral
associate. Since 2007 he has been working
as an Associate Professor at Aix-Marseille
University (France). He passed his Habilita-
tion (HDR) in 2015. His research interests

atropisomeric biaryls. ${ }^{[13]}$ A variety of axially chiral biaryls, heterobiaryls, and tetra-ortho-substituted biaryls were efficiently prepared in high yields with excellent levels of enantiocontrol from readily available substrates. These reactions tolerate a wide scope of heterocycles and functional groups, employ low catalyst loading, and proceed under mild conditions. In addition to this broad substrate scope, the authors also demonstrated the possible access to ternaphthalenes 5a,b via a double Suzuki-Miyaura cross-coupling between dibromonaphthalene $\mathbf{3}$ and naphthylboronic acid $\mathbf{8}$ (Scheme 4). Key to the success of the reaction was the development and application of the very bulky $C_{2}$-symmetric chiral NHC ligand $\mathbf{L} 2$ for the Pd catalyst.

The following year, Baudoin and Cramer reported an atroposelective intermolecular $\mathrm{Pd}$-catalyzed $\mathrm{C}-\mathrm{H}$ arylation of 1,2,3-triazoles and pyrazoles. ${ }^{[14]}$ They used a $\mathrm{Pd}^{0}$ complex with the chiral monodentate phosphine ligand $\mathbf{L 3}$ for the arylation of a broad range of triazoles and pyrazoles in high enantio- 

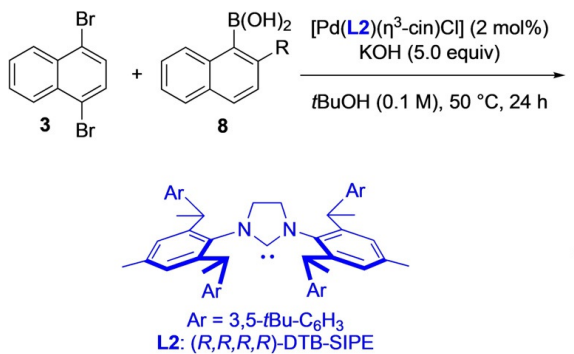

Scheme 4. Enantioselective synthesis of axially chiral ternaphthalenes.

selectivity. Investigations of the deuterium kinetic isotope effect revealed that the $\mathrm{C}-\mathrm{H}$ activation is the rate-determining but not the enantio-determining step. Interestingly, the $\mathrm{C}^{-}$ $\mathrm{H}$ arylation of 1,5-dibromo-2,6-dimethoxynaphthalene (10) with two equivalents of 1-methyl-4-phenyl-1 $H$-1,2,3-triazole (9) allowed the synthesis of the double-axis heteroatropisomer $(M, M)-\mathbf{1 1}$ in good yield $(76 \%)$ and excellent enantiocontrol $(>99 \%$ ee) without formation of the meso stereoisomer (Scheme 5).
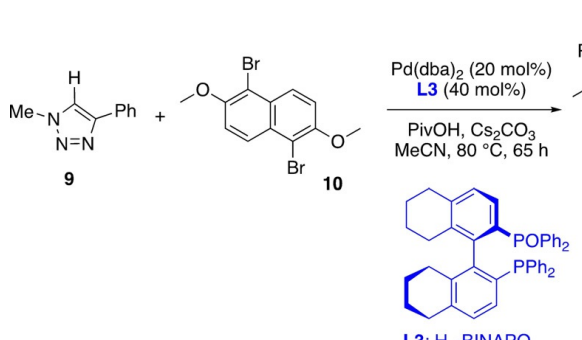

L3: $\mathrm{H}_{8}$-BINAPO

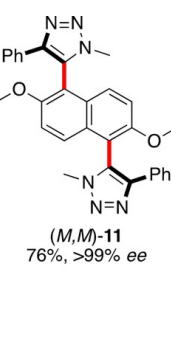

Scheme 5. Atroposelective $\mathrm{Pd}$-catalyzed $\mathrm{C}-\mathrm{H}$ arylation of triazole 9.

\section{2. (2+2+2) Cycloaddition (Type B, C, and D Molecules)}

The $(2+2+2)$ cycloaddition is a privileged, atom-economical protocol for the assembly of substituted benzene rings via metallacyclopentadiene intermediates. It has demonstrated its potential in the enantioselective synthesis of biaryl atropisomers in the presence of chiral transition-metal complexes. $^{[15]}$ In 2004, 15 years after the pioneering work of Hayashi and co-workers, the group of Shibata described the second and general strategy for the enantioselective synthesis of biaryl atropisomers with a 1,4-diaxial arrangement, and reported the full details later (Scheme $6 a$ ). ${ }^{[16]}$ The use of iridium and $(S, S)$-MeDUPHOS $(\mathbf{L 4})$ as the transition-metal complex catalyst successfully achieved the enantioselective $(2+2+2)$ cycloaddition of ortho-substituted diaryldiynes $\mathbf{1 2}$ and alkynes $\mathbf{1 3}$ with various functionalities to afford congested teraryl atropisomers $\mathbf{1 4}$ in good yield and excellent stereoselectivity. Through rational design, the same strategy was further utilized to forge the helically shaped chiral atropisomers 16 with four and eight consecutive axes through a)
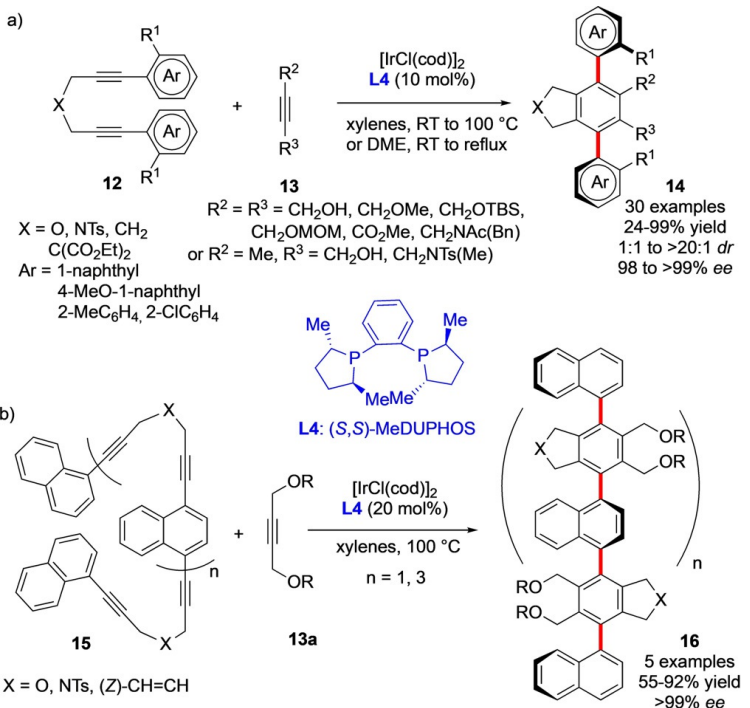

Scheme 6. Enantioselective synthesis of axially chiral teraryl compounds.

the cycloaddition of tetra- to octaynes 15 with alkynes $13 \mathbf{a}$ in perfect enantioselectivity (Scheme 6b). ${ }^{[17]}$

In 2007, in complementary work, Tanaka and co-workers established a similar enantio- and diastereoselective $(2+2+2)$ cycloaddition of diketodiynes $\mathbf{1 7}$ and monoalkynes $\mathbf{1 8}$ to give the teraryl atropisomers $\mathbf{1 9}$ featuring an anthraquinone structure with a 1,4-diaxial subunit in good yield and enantioselectivity (Scheme 7). ${ }^{[18]}$ The diastereomeric ratio ranged from 2:1 to $8: 1$, depending on the substituents of the reaction partners. The authors revealed that the cationic rhodium- $(S)$-SEGPHOS complex used in the reaction was superior to Shibata's iridium-( $S, S)$-MeDUPHOS complex, as the latter failed to catalyze the cycloaddition with the electron-deficient diketodiyne.

Next, with the established catalytic system, examples to construct 1,2- and 1,3-diaxially chiral systems were disclosed (Scheme 8). Alternatively, the enantioselective cycloaddition of 1,6-diyne $\mathbf{2 0}$ with alkynes $\mathbf{2 1}$, featuring a 2-substituted phenyl group and an $\mathrm{N}, \mathrm{N}$-dialkylamino formyl group at the terminus, gave the desired 1,2-diaxially chiral biaryl benzamides 22 in high yield with excellent enantio- and diastereo-

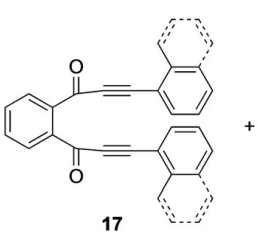

$\mathrm{R}^{1}=\mathrm{Et}, n-\mathrm{Pr}, \mathrm{Me}, \mathrm{CH}_{2} \mathrm{OMe}$ $\mathrm{R}^{2}=\mathrm{Et}, n-\mathrm{Pr}, n-\mathrm{C}_{5} \mathrm{H}_{11}, \mathrm{CH}_{2} \mathrm{OH}$ $\mathrm{CH}_{2} \mathrm{OMe}, \mathrm{CO}_{2} \mathrm{Et}$
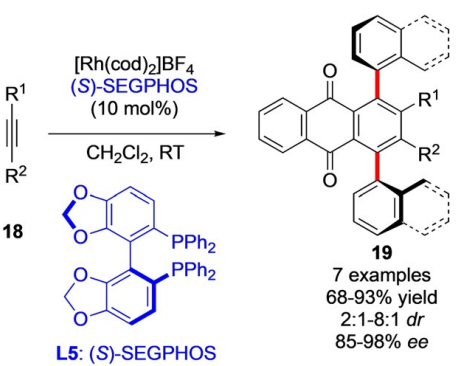

Scheme 7. Enantioselective synthesis of axially chiral anthraquinones. 


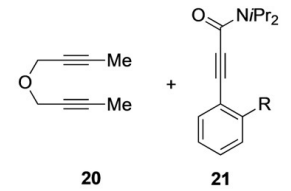

20

21

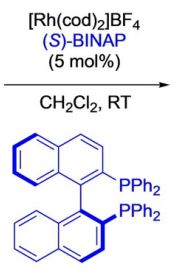

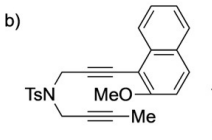

23

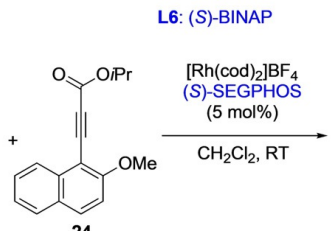

24

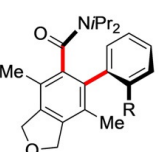

22a: $R=$ Me, $91 \%$ yield $>20: 1 d r,>99 \%$ ee 22b: $\mathrm{R}=\mathrm{Br}, 86 \%$ yield
$>50: 1 \mathrm{dr} r>99 \%$ ee

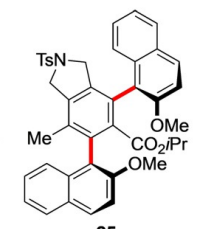

89\% yield, $2.5: 1 \mathrm{dr}, 87 \%$ ee

Scheme 8. Enantioselective synthesis of 1,2- and 1,3-diaxially chiral arenes.

selectivity in the presence of the rhodium- $(S)$-L6 complex as catalyst (Scheme 8a). ${ }^{[19]}$ In addition, the enantioselective cycloaddition of 2-methoxynaphthalene-derived 1,6-diyne $\mathbf{2 3}$ and 2-methoxynaphthalene alkynylester $\mathbf{2 4}$ with rhodium- $(S)$ SEGPHOS (rhodium- $(S)$-L5) afforded the 1,3-teraryl, 1,3diaxial compound $\mathbf{2 5}$ as a major diastereomer with good yield and enantioselectivity (Scheme 8b). ${ }^{[20]}$

Following their previous work, Shibata and co-workers also developed an enantioselective intramolecular $(2+2+2)$ cycloaddition in 2006 (Scheme 9). ${ }^{[21]}$ The same iridium- $(S, S)$ MeDUPHOS complex (see Scheme 6) smoothly catalyzed the intramolecular cyclotrimerization of various triynes $\mathbf{2 6}$ with terminal ortho-substituted aryl groups, affording the desired biaryl, 1,2-diaxial atropisomers $\mathbf{2 7}$ in good yield and enantioselectivity.
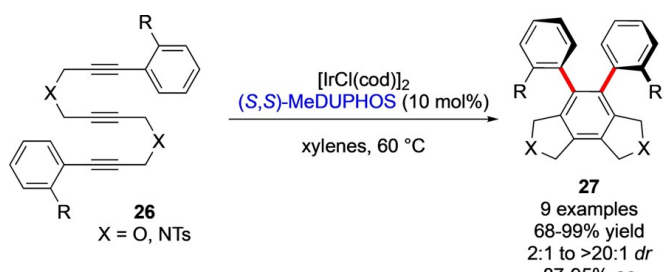

Scheme 9. Enantioselective synthesis of axially chiral ortho-diarylbenzene.

In related work, an interesting rhodium-( $S)$-xylyl-BINAPcatalyzed enantioselective intermolecular $(2+2+2)$ cycloaddition of ynamides $\mathbf{2 8}$ and alkynes $\mathbf{2 9}$ was disclosed in 2007 by Hsung and co-workers towards the chiral, ortho-disubstituted $\mathrm{N}, \mathrm{O}$-biaryls 30 (Scheme 10). ${ }^{[22]}$ This was the first example in which both the $\mathrm{C}-\mathrm{C}$ and $\mathrm{C}-\mathrm{N}$ axial chirality was set in one step, and the process provided the final product in good yield and enantioselectivity, even though the diastereocontrol was not perfect.

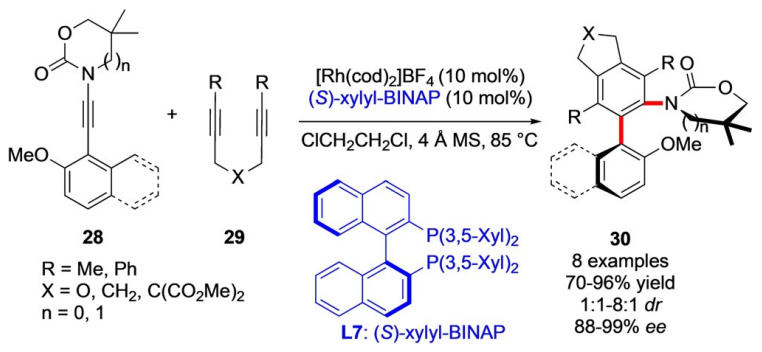

Scheme 10. Enantioselective synthesis of axially chiral $\mathrm{C}-\mathrm{C}$ and $\mathrm{C}-\mathrm{N}$ atropisomers.

\subsection{Dynamic Kinetic Resolution (Type A and C Molecules)}

In recent years, the dynamic kinetic resolution (DKR) of racemic compounds has emerged as one of the most efficient methodologies for the synthesis of enantio-enriched atropisomers. ${ }^{[23]}$ In this context, following their innovative work in this area, ${ }^{[24 a]}$ Miller and co-workers generated in 2014 a unique 1,1-diaxially chiral system through the enantioselective bromination of racemic benzamide $\mathbf{3 1}$ to give the corresponding tribromides $\mathbf{3 2}$ in the presence of the peptide catalyst $\mathbf{I}$ and 1,3-dibromo-5,5-dimethylhydantoin (DBDMH). ${ }^{[24 b]}$ The amide 32 features an $\mathrm{Ar}-\mathrm{CO}$ axis (in red) and a $\mathrm{C}-\mathrm{N}$ axis (in blue), connected to each other directly (Scheme 11).
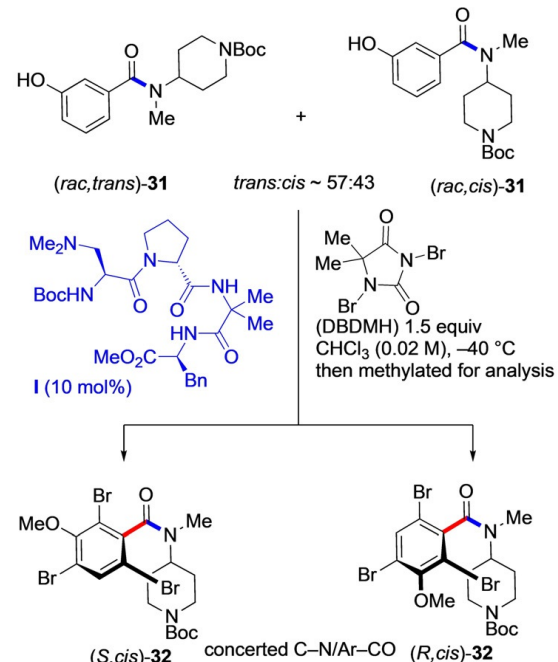

(S, cis)-32 concerted C-N/Ar-CO (R,cis)-32
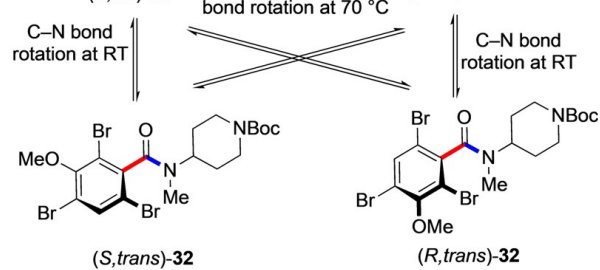

After quench: $2 \mathrm{~h}$, trans:cis $=43.57$, er $r_{\text {trans }}=66: 34$, er $=88.12$ $10 \mathrm{~h}$, trans:cis $=54.46, \mathrm{er}=72.28, \mathrm{er}=86.14$ $24 \mathrm{~h}$, trans:cis $=68: 32$, er trans $^{2}=77: 23$, er $r_{\text {cis }}=84: 16$ $72 \mathrm{~h}$, trans: cis $=76: 24, \mathrm{er}_{\text {trans }}=79: 21, \mathrm{er}_{\mathrm{cis}}=79: 21$

Scheme 11. Enantioselective synthesis of unique chiral benzamide. 
Interestingly, a kinetically controlled product distribution was observed initially, as ( $S$-cis)-32 was detected to be the major product (trans:cis $=43: 57$ ) $2 \mathrm{~h}$ after the reaction had been quenched, while cis-31 was the minor product (trans:cis= 57:43) at the onset. Moreover, an isomerization of this system occurred at room temperature and the thermodynamic equilibrium was reached after $72 \mathrm{~h}$. As observed, the trans:cis ratio increased from 43:57 to 76:24, and both $e r_{\text {trans }}$ and $e r_{c i s}$ reached 79:21 from 66:34 and 88:12, respectively. This equilibrium was the result of the $\mathrm{C}-\mathrm{N}$ bond rotation at room temperature $[(S$-cis $)-\mathbf{3 2}$ to $(S$-trans $)-\mathbf{3 2}$, and $(R$-cis $)-\mathbf{3 2}$ to $(R$ trans)-32], which was circumstantially supported by X-ray structure analysis and DFT calculations. In addition, the authors confirmed that a concerted $\mathrm{C}-\mathrm{N} / \mathrm{Ar}-\mathrm{CO}$ bond rotation was responsible for the racemization of the amide 32 at higher temperature.

Later in 2019, Smith and co-workers established an elegant chiral counterion-mediated $O$-alkylation of atropisomeric amides in high enantioselectivity via DKR, and two interesting examples for the incorporation of two stereogenic axes were described (Scheme 12). ${ }^{[25]}$ The key racemization process at the $\mathrm{Ar}-\mathrm{CO}$ axis (in red) of $\mathbf{3 3}$ was facilitated by the intramolecular $\mathrm{O}^{-} \mathrm{H} \cdots \mathrm{NCO}$ hydrogen bond, which was demonstrated by quantum calculations. Thus, with the preinstalled ortho-substituted aryl group at the 8-position, the enantioselective $O$-alkylation of $\mathbf{3 3}$ catalyzed by catalyst II enabled the generation of 1,3-diaxial chiral amides 34 with in good yields and high enantioselectivities for both diastereomers.

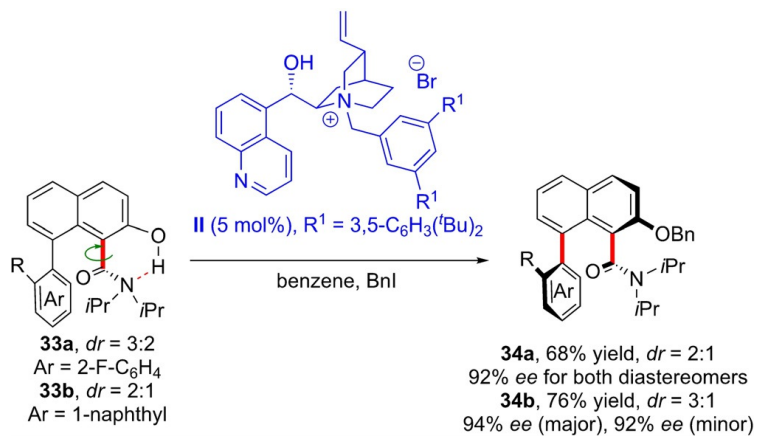

Scheme 12. Enantioselective $O$-alkylation of atropisomeric amides.

\subsection{Central-to-Axial Chirality Conversion (Type B, C, D, and E Molecules)}

Central-to-axial chirality conversion has attracted much attention and has been used by several groups in recent years to forge and control axial chirality. ${ }^{[26]}$ First hypothesized in 1955 by Berson, it was established by Meyers 30 years later in a diastereoselective approach. ${ }^{[27]}$ In 2016, Sparr and coworkers developed a compelling and efficient enantioselective aldol condensation for the construction of oligo-1,2 naphthylenes with one stereogenic axis (Scheme 13). ${ }^{[28]}$ The natural amino acid L-isoleucine catalyzed the stereoselective intramolecular aldol addition of the in situ double-oxidation product of $\mathbf{3 5}$, and the conversion of the central chirality to
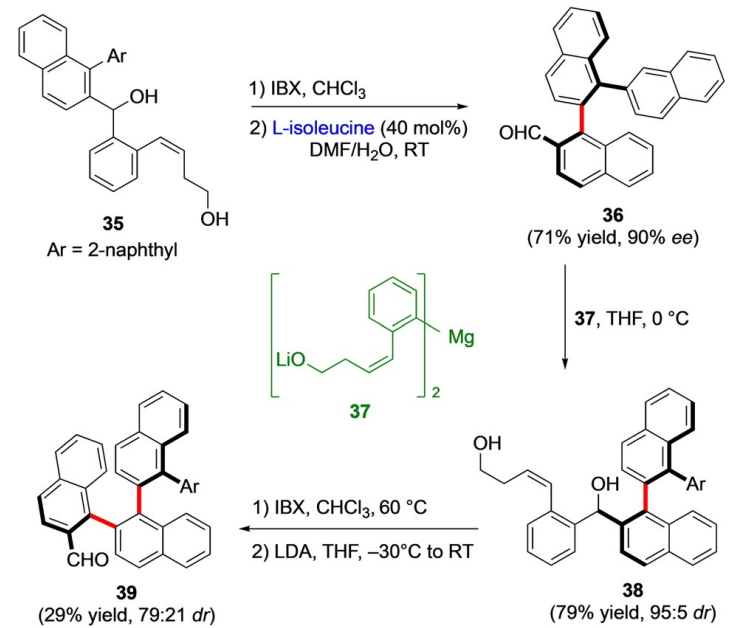

Scheme 13. Enantioselective synthesis of oligo-1,2-naphthylenes.

the axial chirality during the dehydrative arene-forming process afforded the oligoarene $\mathbf{3 6}$ in $71 \%$ yield and $90 \%$ $e e$. To generate the second axis, a mixed-metal species $\mathbf{3 7}$, the building block for the preparation of $\mathbf{3 5}$, was added to build a similar aldol addition precursor unit $\mathbf{3 8}$. Thus, the in situ double-oxidation and the substrate-controlled diastereoselective arene-forming aldol condensation sequence formed the atropisomers 39 featuring two stereogenic axes with 1,2arrangement and a secondary $P$-helix substructure in $29 \%$ yield and 79:21 $d r$.

To circumvent the low yield and diastereoselectivity, the authors developed recently a catalyst-controlled stereodivergent synthesis of extended oligomers with multiple stereogenic axes (Scheme 14). The strategy profited from the established iterative building block addition/stereoselective aldol sequence. ${ }^{[29]}$ The catalyst-controlled stereodivergent synthesis, in which the obstacle is the catalyst-substrate mismatch, is a well-explored concept in the construction of molecules with multiple stereogenic centers. ${ }^{[30]}$ In sharp contrast, this concept was unrecognized when the molecule contained two or more stereogenic axes until this seminal work was addressed. First, the in situ double oxidation of diol 40 followed by a $(S)$-pyrrolidinyl tetrazole III catalyzed enantioselective arene-forming aldol condensation afforded the biaryl atropisomer $\left(S_{a}\right)$-41 in over 99:1 er. As demonstrated in Scheme 14, the chain elongation of $\left(S_{a}\right)-\mathbf{4 1}$ could be rapidly enabled by the mixed-metal species $\mathbf{3 7}$ to give the diol 42. Therefore, the $\left(R_{a}, S_{a}\right)$-43 with two stereogenic axes was accessed via the similar procedure without catalyst in 4:1 $d r$, which can be improved to $16: 1$ by the cinchonidine-derived catalyst IV. Intriguingly, the catalyst III inverted the selectivity to give the $\left(R_{a} S_{a}\right)-\mathbf{4 4}$ as the major product in 32:1 dr (catalyst-substrate mismatch). With the same strategy, the substrate-controlled $\left(R_{\mathrm{a}}, S_{\mathrm{a}}, S_{\mathrm{a}}\right)-\mathbf{4 5}$ with three stereogenic axes was afforded in 7:1 $d r$. However, the ion-pairing catalyst IV proffered to give the mismatched stereoisomer $\left(S_{\mathrm{a}}, S_{\mathrm{a}}, S_{\mathrm{a}}\right)-\mathbf{4 6}$ in $8: 1 d r$ in this case. In addition, stereoisomers $\left(R_{a}, S_{a}, S_{a}, S_{a}\right)-\mathbf{4 7}$ and $\left(S_{a}, S_{a}, S_{a}, S_{a}\right)$-48 with up to four stereogenic axes were 

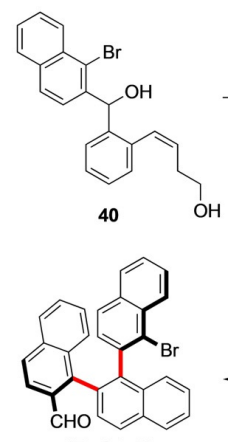

$\left(R_{a}, S_{a}\right)-\mathbf{4 3}$

$(69 \%$ yield, $16: 1 d r)$ (without catalyst

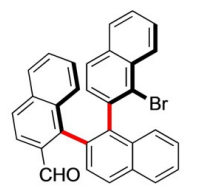

$\mathrm{CHCl}_{3} / \mathrm{DMF}$
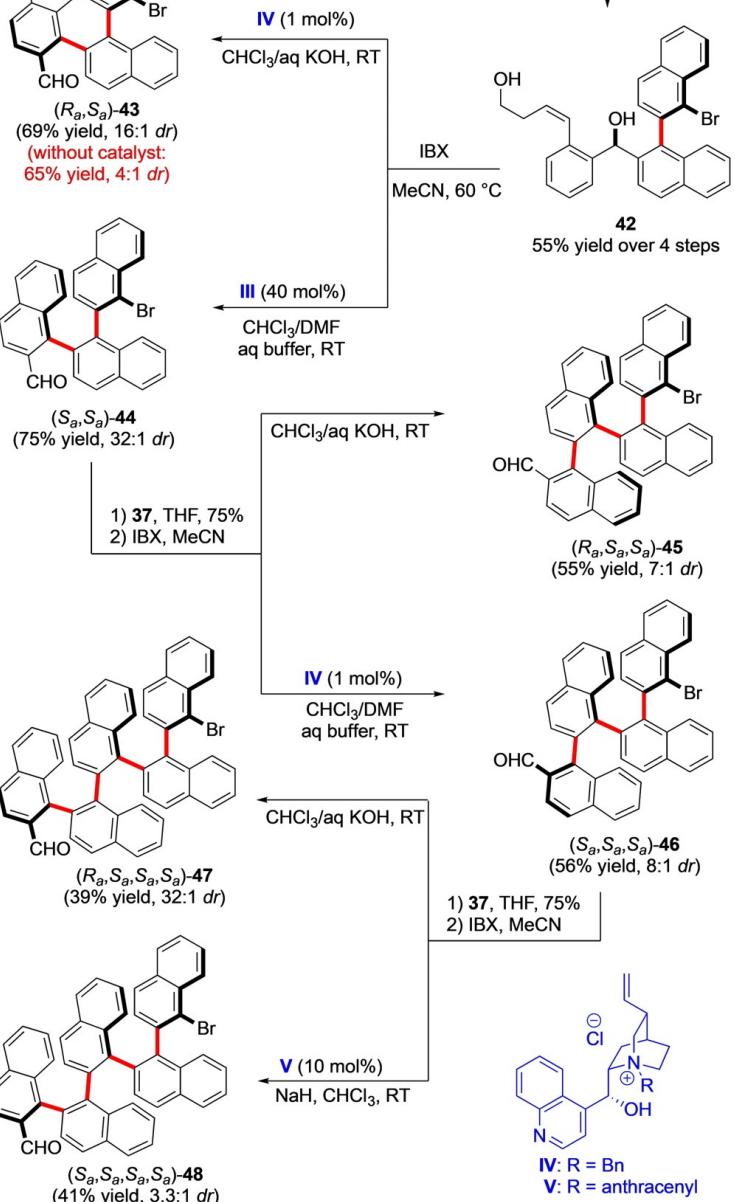

42

$55 \%$ yield over 4 steps

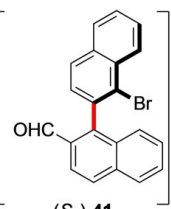
$\left(S_{a}\right)-41$
$(>99: 1 \mathrm{er})$

37, THF, $0^{\circ} \mathrm{C}$ 37, THF, $0^{\circ} \mathrm{C}$
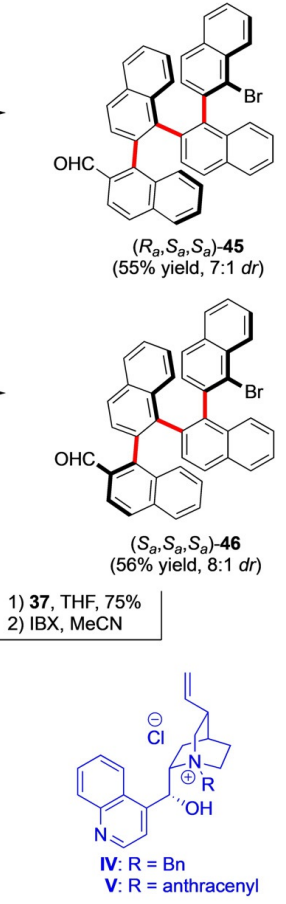

Scheme 14. Stereodivergent synthesis of oligomers with multiple stereogenic axes.

achieved efficiently. This compelling stereodivergent synthesis of atropisomers with multiple stereogenic axes endows the corresponding oligoarenes with a unique and promising topology. In addition, the electron-transfer property associated with the conjugation of this unique class of helical oligo1,2-naphthylenes with $\left[\mathrm{Ru}(\mathrm{bpy})_{3}\right]^{2+}$ photosensitizer was investigated recently. ${ }^{[31]}$

Later in 2019, Zhou and co-workers reported a stepwise strategy to synthesize chiral 2,3-diarylbenzoindoles $\mathbf{5 2}$ featuring two stereogenic axes with a 1,2-arrangement in good yield and excellent stereoselectivity (Scheme 15). ${ }^{[32]}$ The chiral

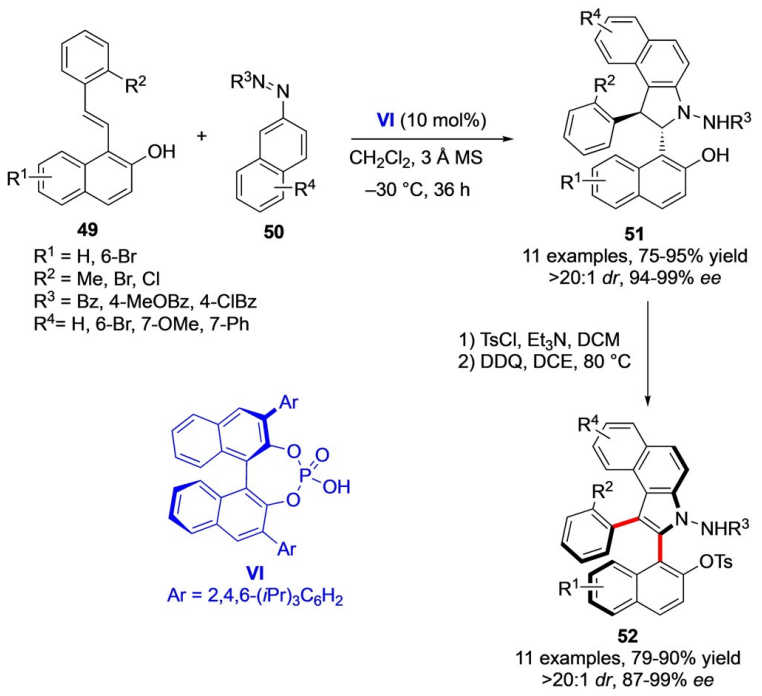

Scheme 15. Enantioselective synthesis of axially chiral 2,3-diarylbenzoindoles.

phosphoric acid (CPA) VI catalyzed the formal $(3+2)$ cycloaddition of 1-styrylnaphthols $\mathbf{4 9}$ with azonaphthalenes $\mathbf{5 0}$ to construct the enantiomerically enriched dihydropyrrole precursors 51 in good yield and excellent diastereo- and enantioselectivity. Next, the oxidative aromatization with dichlorodicyanobenzene (DDQ) under mild conditions efficiently afforded the diarylbenzoindoles $\mathbf{5 2}$ through central-toaxial chirality conversion after the protection of phenolic hydroxyl group with $p$-toluene sulfonyl (Ts) group. Notably, this well-designed process was the first example of the conversion of two adjacent stereogenic centers into two ortho-stereogenic axes.

Recently, a bidirectional enantioselective synthesis of bisbenzofuran atropisomeric oligoarenes was reported by our group (Scheme 16). Oligoarenes 58 (S-shaped) and 59 (Eshaped) featuring two distal stereogenic axes were obtained in good yield and stereoselectivity by a twofold central-toaxial chirality conversion from the oxidative aromatization of bis-dihydrobenzofuran precursors 56 and 57 with $\mathrm{MnO}_{2}$ respectively. ${ }^{[33]}$ The bis-dihydrobenzofuran precursors were constructed thanks to a chiral squaramide VII catalyzed bidirectional stereoselective Michael addition/O-cyclization cascade of simple dihydroxylated aromatics $\mathbf{5 3}$ or $\mathbf{5 4}$ and chloronitroalkenes 55. The high level of enantioselectivity was due to the beneficial Horeau chiral amplification effect. Moreover, this bidirectional property facilitated a stereodivergent approach to nonsymmetrically functionalized Sshaped oligoarenes (Scheme 17). The mono-dihydrobenzofuran $\mathbf{6 0}$ was formed with one equivalent of chloronitroolefin 55a in $55 \%$ yield and excellent stereoselectivity ( $>20: 1 d r$, $96 \% e e$ ). Next, the second dihydrobenzofuran motif was forged with chloronitroolefin 55b utilizing VII or ent-VII to give the stereoisomers $(2 S, 3 S, 7 S, 8 R)-\mathbf{6 1}$ and $(2 R, 3 R, 7 S, 8 R)$ 62, respectively, in good yield and excellent diastereo- and enantioselectivities. Gratifyingly, the efficient chirality con- 


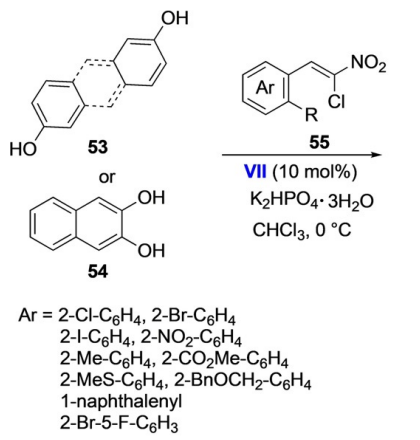

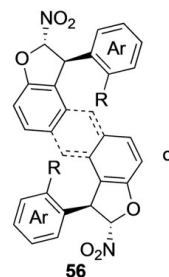

${ }_{56} \mathrm{O}_{2} \mathrm{~N}$

11 examples $50-86 \%$ yield 96 to $>99 \%$ ee

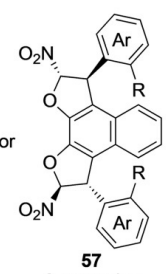

3 examples $64-83 \%$ yield
$1.4: 1-3.8: 1 d r$ $70-95 \%$ ee

$\mathrm{MnO}_{2}$, toluene, $0^{\circ} \mathrm{C}$

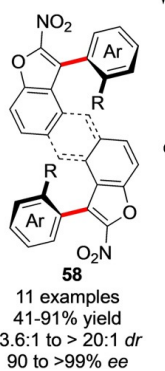

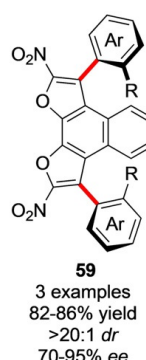

82-86\% yield $>20: 1 d r$

Scheme 16. Enantioselective synthesis of bis-benzofuran atropisomers.

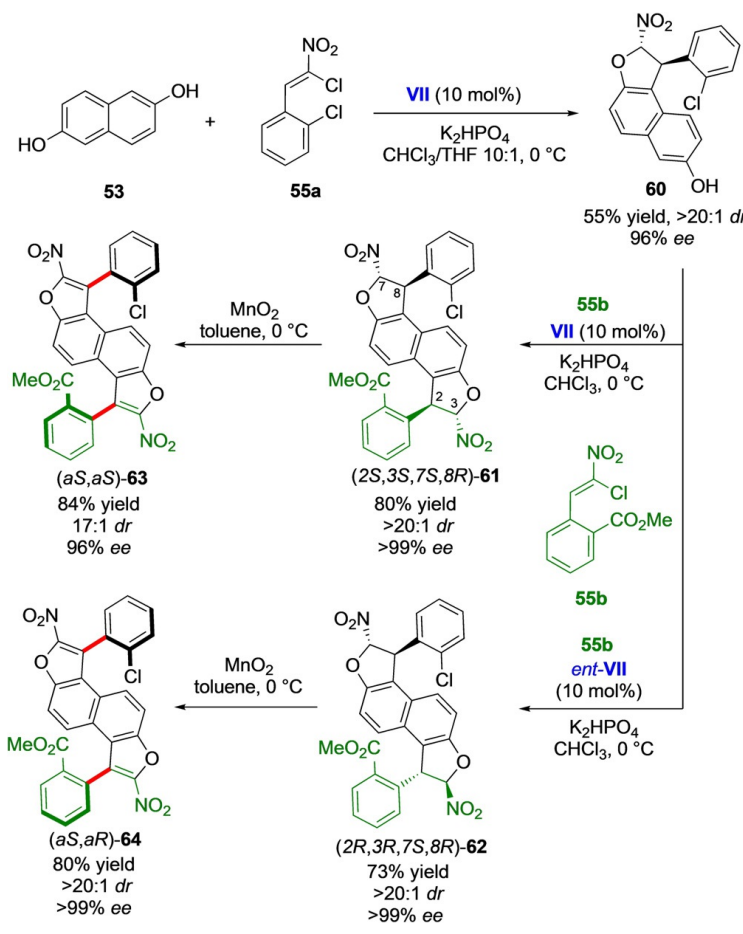

Scheme 17. Stereodivergent synthesis of bis-benzofuran atropisomers.

version process afforded the corresponding bis-benzofuran diastereomers $(\mathrm{a} S, \mathrm{a} S)-\mathbf{6 3}$ and $(\mathrm{a} S, \mathrm{a} R)-\mathbf{6 4}$ in good yields and both with excellent enantiocontrols via oxidative aromatization.
Very recently, Bertuzzi and co-workers developed a closely related central-to-axial chirality conversion approach to construct enantiomerically enriched indole-quinoline atropisomers. ${ }^{[34]}$ As an extension of this methdology, two examples of 1,3-diaxially chiral atropisomers were constructed (Scheme 18). The use of CPA VIII as the organocatalyst directly furnished the tetrahydroquinoline $6 \mathbf{6} \mathbf{a}$ in good yield and enantioselectivity via an enantioselective Povarov (4+2)cycloaddition of 3-alkenylindole $\mathbf{6 5}$ and $N$-arylimine $\mathbf{6 6}$ a Then the oxidative aromatization with DDQ triggered the chirality conversion step, affording the indole-quinoline atropisomers 68 a in $59 \%$ yield and $94 \%$ enantiomeric excess. In addition, the moderate $3: 1$ diastereomeric ratio was the result of the lower chirality conversion to the second axis. Similarly, the tetrahydroquinoline $\mathbf{6 7 b}$ with two indole moieties was obtained in good yield and enantioselectivity from imine $66 \mathrm{~b}$ with VI as the catalyst. Interestingly, the second stereogenic axis with a five-membered indole ring was not configurationally stable at room temperature. Thus, the subsequent oxidation with $m$-CPBA afforded the final $N$ oxide $68 \mathbf{b}$ featuring two stereogenic axes with 1,3-arrangement in $60 \%$ yield and good stereoselectivity $(9.4: 1 d r, 90 \%$ ee).

Finally, in 2020, Tan and co-workers reported the first CPA-catalyzed atroposelective $\mathrm{C}-\mathrm{H}$ amination of electrophilic azoarenes with nucleophilic pyrroles and carbazoles ${ }^{[35]}$

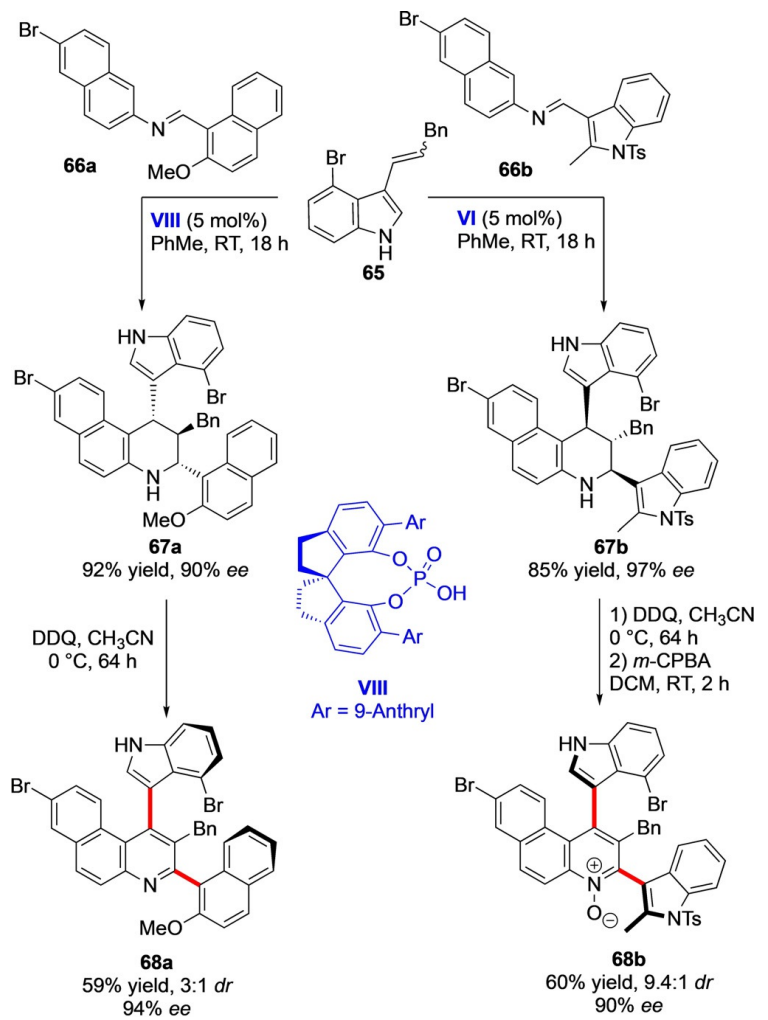

Scheme 18. Enantioselective synthesis of indole-quinoline atropisom ers. 
in which an organized hydrogen-bond network activates both the azoarene and the substituted heterocycle. ${ }^{[36]}$ During the following rearomatization a central-to-axial chirality conversion is in effect, and the $\mathrm{C}-\mathrm{H}$ functionalized axially chiral arene is obtained in high atroposelectivity. A double enantioselective arene $\mathrm{C}-\mathrm{H}$ amination reaction was conducted with success with $(S)$-IX, from 2,6-diazonaphthalene $\mathbf{6 9}$ and carbazoles $\mathbf{7 0}$ as the nucleophiles to give the desired 1,5dicarbazole naphthalene derivatives $\mathbf{7 1}$ with excellent enantiocontrol (Scheme 19), and only moderate formation of the meso product $(d r=4: 1)$.
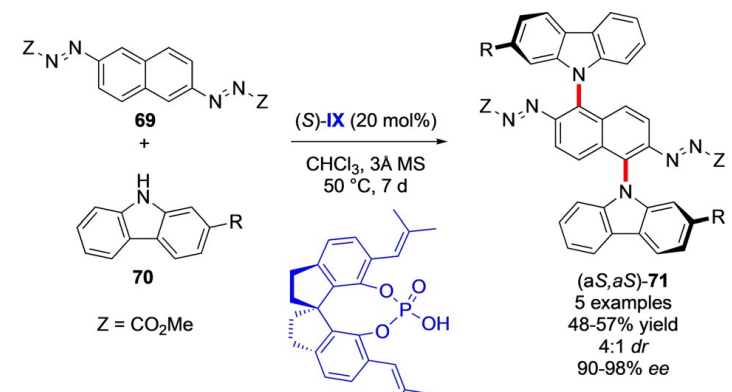

Scheme 19. Atroposelective $\mathrm{C}-\mathrm{H}$ double amination of azoarenes.

\subsection{Trapping Vinylidene-Quinone Methides (Type B, D, and E Molecules)}

Vinylidene-quinone methides (VQMs) were synthesized and identified for the first time in 2012 by Freccero and utilized by the group of Irie in 2013 for the first atroposelective transformation. ${ }^{[37]}$ In recent years, these intriguing highly electrophilic intermediates have shown their huge potential for the construction of axially chiral compounds. ${ }^{[38]}$ A critical feature of VQMs is their intrinsic axial chirality, which can be controlled during their generation from 2alkynylnaphthols with a chiral nonracemic organocatalyst. In this context, the group of Yan developed a series of elegant methods for the enantioselective synthesis of atropisomers. ${ }^{[39]}$ In 2018, this group disclosed a bidirectional enantioselective construction of 1,4-diaxially chiral bis-styryl diols $\mathbf{7 4}$ from 1,4dialkynylnaphthalene-2,3-diols $\mathbf{7 2}$ with organocatalyst $\mathbf{X}$ (Scheme 20). ${ }^{[39 b]}$ First, the chiral VQMs-1 intermediate was generated through an enantioselective prototropic rearrangement in the presence of squaramide catalyst $\mathbf{X}$. Next, bidirectional addition of in situ generated sulfone anion from $\alpha$-amido sulfone $\mathbf{7 3}$ to VQMs-1 gave the diols $\mathbf{7 4}$ in good yield and excellent stereoselectivity. A preliminary study was conducted to show the potential of these chiral diols as chiral ligands.

At the same time, they achieved a more complex system with up to three stereogenic axes by an enantioselective threecomponent reaction (Scheme 21). ${ }^{[3 \mathrm{~d}]}$ The highly reactive transient iodo-substituted chiral VQMs-2 intermediate was generated by the squaramide $\mathbf{X I - c a t a l y z e d ~ e n a n t i o s e l e c t i v e ~}$ electrophilic substitution of alkynylphenols $\mathbf{7 5}$ with $\mathrm{N}$-iodo-

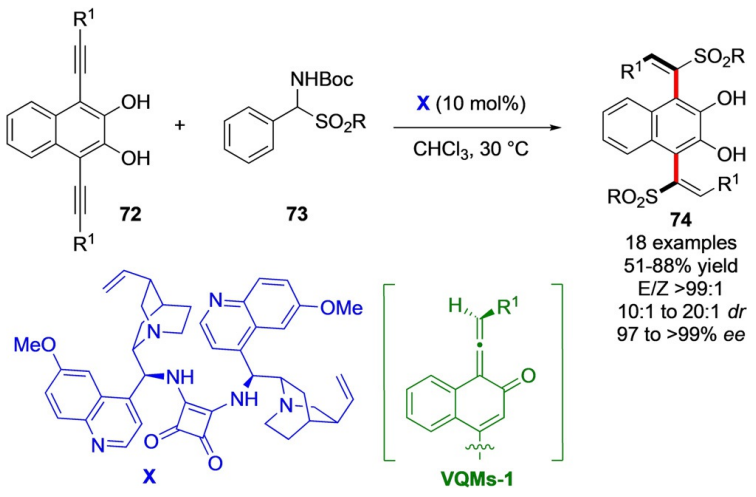

Scheme 2o. Enantioselective synthesis of axially chiral bis-styryl diols.

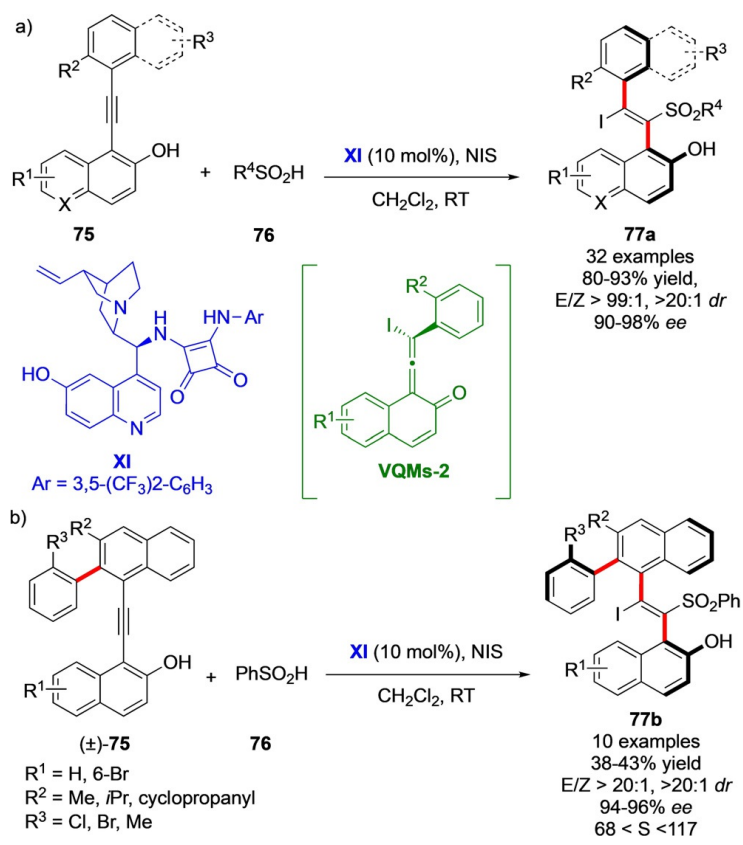

Scheme 21. Enantioselective synthesis of axially chiral styrenes.

succinimide (NIS). Thereafter, the trapping of this intermediate with sulfinic acid $\mathbf{7 6}$ afforded the vicinal styrenes $\mathbf{7 7} \mathbf{a}$ with two stereogenic axes with a 1,2-arrangement in good yields and excellent stereochemical outcome (Scheme 21 a). Moreover, the standard conditions were efficient for the kinetic resolution of racemic axially chiral substrates $\mathbf{7 5}$, affording the final styrenes $\mathbf{7 7} \mathbf{b}$, which feature three stereogenic axes, with selectivity factors higher than 68 (Scheme 21b).

Continuing this work, the same group stepped forward to demonstrate a smart design for the synthesis of optically active carbo[6]helicenes $\mathbf{7 9}$ featuring two distal stereogenic axes (Scheme 22). ${ }^{[39 \mathrm{~g}]}$ The organocatalyst $\mathbf{X}$ efficiently transferred the rationally designed ortho-alkynylphenols $\mathbf{7 8}$ to helicenes $\mathbf{7 9}$ with high diastereo- and enantioselectivity via the corresponding chiral VQM intermediate VQMs-3. In 


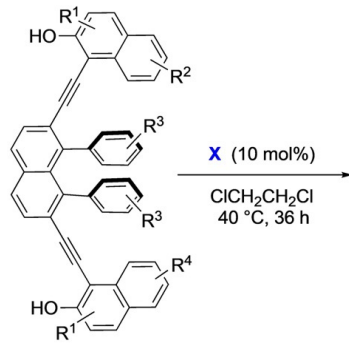

78

$\mathrm{R}^{3}=3,5-2-\mathrm{OMe}, 3-\mathrm{OMe}$

$3,4-\left(\mathrm{OCH}_{2}\right)_{2}$

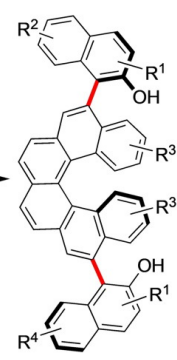

$(P, 5 a R, 12 a R)-79$ 14 examples
$81-96 \%$ yield $81-96 \%$ yield
$7: 1$ to $>20: 1$ $99 \%$ ee
(1)

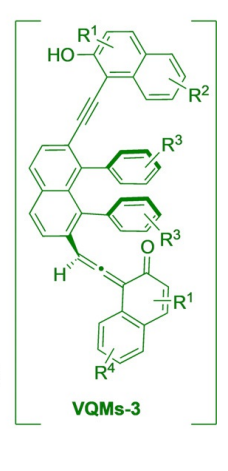

Scheme 22. Enantioselective synthesis of axially chiral [6]helicenes.

addition, mechanistic studies revealed that the first cyclization produced a reaction intermediate containing a stereogenic axis. This was evidenced by the isolation of the monocyclization product $\mathbf{8 0}$ with $99 \%$ ee after only $8 \mathrm{~h}$ of reaction (Scheme 23). The remaining helix and stereogenic axis were
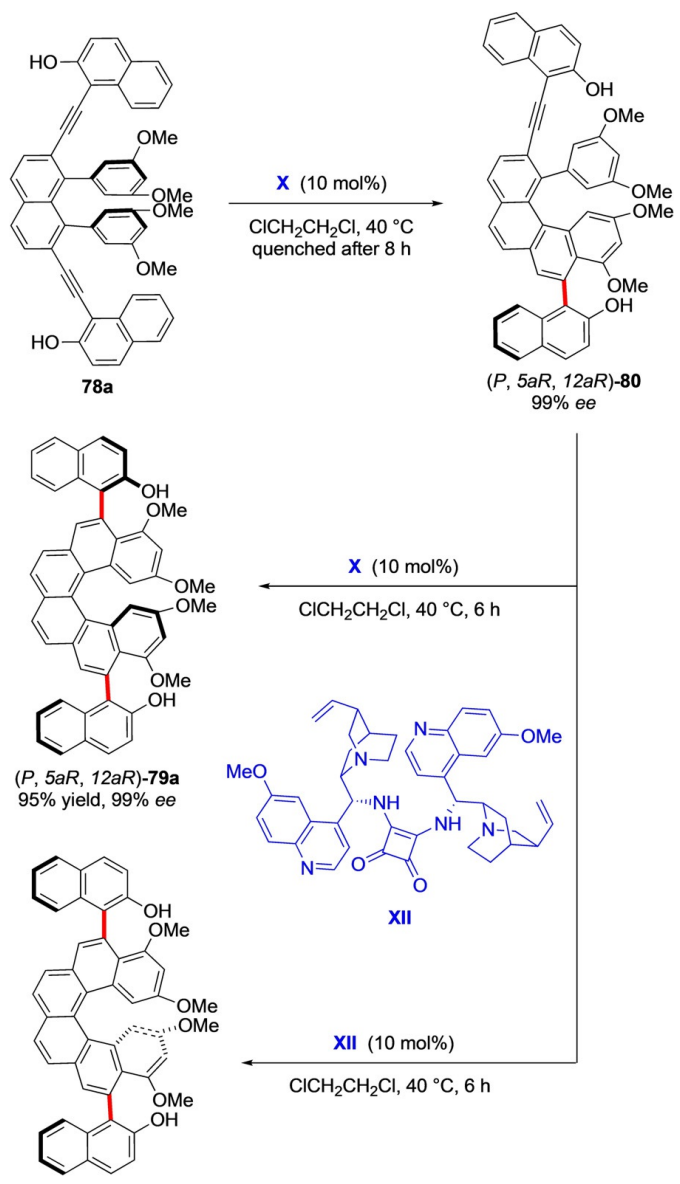

XII

XII (10 mol\%)

$\mathrm{ClCH}_{2} \mathrm{CH}_{2} \mathrm{Cl}, 40^{\circ} \mathrm{C}, 6 \mathrm{~h}$

$(M, 5 a R, 12 a S)-81$

$85 \%$ yield, $95 \%$ ee

Scheme 23. Stereodivergent synthesis of axially chiral [6]helicenes. generated through a dynamic kinetic resolution. This work featured a stereodivergent approach to access the diastereomers of this intriguing scaffold through catalyst control. As shown in Scheme 23, the helicene $(P, 5 a R, 12 a R)-79$ a and its diastereomer $(M, 5 a R, 12 a S)$-81 were generated from the monocyclization product $\mathbf{8 0}$ in good yields and excellent enantioselectivities in the presence of $\mathbf{X}$ and its pseudoenantiomer XII, respectively.

\subsection{Miscellaneous (Type D and E Molecules)}

Very recently, Shibata and co-workers reported a cycloisomerization strategy closely related to a $(2+2+2)$ cycloaddition for the enantioselective synthesis of mono- and bisaxially chiral polycylic hydrocarbons (PAHs). ${ }^{[40]}$ A dibenzometallacyclopentadiene complexe intermediate $\mathbf{8 3}$ is generated from $82 \mathbf{a}-\mathbf{c}$ by regioselective cleavage of the biphenylene units assisted by the alkyne moiety, in the presence of a rhodium catalyst and the diene ligand L7. Then, a bidirectional enantioselective insertion of the alkyne moiety into the $\mathrm{Rh}-\mathrm{C}$ bond, followed by reductive elimination terminates the double cyclization affording the desired PAHs $\mathbf{8 4} \mathbf{a}-\mathbf{c}$ in good yields and only little formation of the meso diastereomers (Scheme 24).
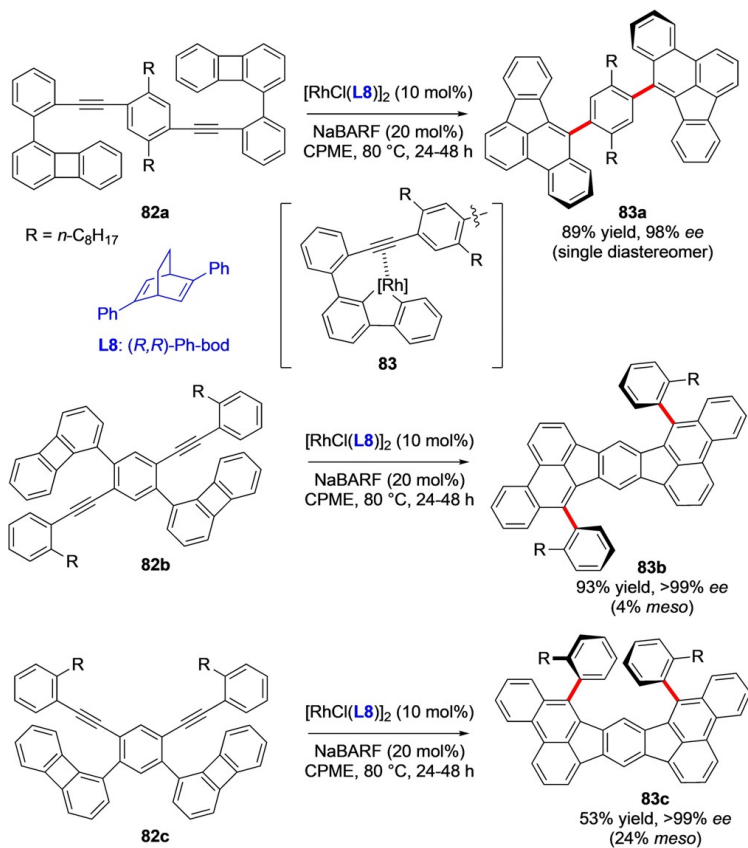

Scheme 24. Enantioselective synthesis of bis-axially chiral PAHs.

\section{Summary and Outlook}

The first glimpses of the tremendous potential of the enantioselective synthesis of atropisomers possessing multiple stereogenic axes have been possible in recent years. 
Innovative methods for the elaborate assemblage of atropisomers with multiple axes have overcome the often low configurational stability of the stereogenic bond and the difficulty of the stereochemical control. Spurred on by the intriguing topologies of these multiple-axis systems, the future will witness the continuous development of their enantioselective synthesis. However, the stereodivergency, for which many smart solutions have been developed over the years for multiple stereogenic centers containing molecules, is still in its infancy for multiple axially chiral atropisomers and remains a huge synthetic challenge. This unique class of atropisomers is expected to have new applications in different fields, following the increasing diversity of the multiple axially chiral scaffolds available.

\section{Acknowledgements}

Financial support from Zhejiang University of Technology, Aix-Marseille Université, the Centre National de la Recherche Scientifique (CNRS), and Centrale Marseille is gratefully acknowledged.

\section{Conflict of interest}

The authors declare no conflict of interest.

[1] Oki defined atropisomers as conformers that interconvert with a half-life of more than 1000 seconds, corresponding to an enantiomerization barrier of $93 \mathrm{~kJ} \mathrm{~mol}^{-1}$ at room temperature. M. Oki, Top. Stereochem. 1983, 14, 1-81.

[2] a) B. K. Lombe, D. Feineis, G. Bringmann, Nat. Prod. Rep. 2019, 36, 1513-1545; b) G. Bringmann, T. Gulder, T. A. M. Gulder, M. Breuning, Chem. Rev. 2011, 111, 563-639.

[3] a) W. Fu, W. Tang, ACS Catal. 2016, 6, 4814-4858; b) T. Akiyama, K. Mori, Chem. Rev. 2015, 115, 9277-9306; c) D Parmar, E. Sugiono, S. Raja, M. Rueping, Chem. Rev. 2014, 114 , 9047-9153; d) Y. Chen, S. Yekta, A. K. Yudin, Chem. Rev. 2003, 103, 3155-3211; e) R. Noyori, Acc. Chem. Res. 1990, 23, $345-$ 350 .

[4] a) D.-W. Zhang, M. Li, C.-F. Chen, Chem. Soc. Rev. 2020, 49 $1331-1343$; b) L. Pu, Acc. Chem. Res. 2012, 45, 150-163.

[5] For selected reviews, see: a) A. J. Metrano, S. J. Miller, Acc. Chem. Res. 2019, 52, 199-215; b) G. Liao, T. Zhou, Q.-J. Yao, B.F. Shi, Chem. Commun. 2019, 55, 8514-8523; c) A. Link, C. Sparr, Chem. Soc. Rev. 2018, 47, 3804-3815; d) B. Zilate, A. Castrogiovanni, C. Sparr, ACS Catal. 2018, 8, 2981 -2988; e) Y.B. Wang, B. Tan, Acc. Chem. Res. 2018, 51, 534-547; f) D. Bonne, J. Rodriguez, Chem. Commun. 2017, 53, 12385-12393; g) E. Kumarasamy, R. Raghunathan, M. P. Sibi, J. Sivaguru, Chem. Rev. 2015, 115, 11239-11300; h) J. Wencel-Delord, A Panossian, F. R. Lerouxb, F. Coloberta, Chem. Soc. Rev. 2015, 44, $3418-3430$; i) G. Bringmann, A. J. P. Mortimer, P. A. Keller, M. J. Gresser, J. Garner, M. Breuning, Angew. Chem. Int. Ed. 2005, 44, 5384-5427; Angew. Chem. 2005, 117, 5518-5563.

[6] a) K. Takaishi, K. Iwachido, R. Takehana, M. Uchiyama, T. Ema, J. Am. Chem. Soc. 2019, 141, 6185-6190; b) Y.-Y. Zhu, X.-D. Wu, S.-X. Gu, L. Pu, J. Am. Chem. Soc. 2019, 141, 175-181; c) R. Mitra, J. Niemeyer, ChemCatChem 2018, 10, 1221 -1234; d) Y.L. Wu, F. Ferroni, S. Pieraccini, W. B. Schweizer, B. B. Frank, G. P. Spada, F. Diederich, Org. Biomol. Chem. 2012, 10, $8016-$
8026; e) X.-H. Chen, W.-Q. Zhang, L.-Z. Gong, J. Am. Chem. Soc. 2008, 130, 5652-5653; f) M. Shibasaki, S. Matsunaga, Chem. Soc. Rev. 2006, 35, 269-279.

[7] S. Fayez, J. Li, D. Feineis, L. A. Assi, M. Kaiser, R. Brun, M. A. Anany, H. Wajant, G. Bringmann, J. Nat. Prod. 2019, 82, $3033-$ 3046.

[8] S. H. Watterson, G. V. De Lucca, Q. Shi, C. M. Langevine, Q. Liu, D. G. Batt, M. Beaudoin Bertrand, H. Gong, J. Dai, S. Yip, P. Li, D. Sun, D.-R. Wu, C. Wang, Y. Zhang, S. C. Traeger, M. A Pattoli, S. Skala, L. Cheng, M. T. Obermeier, R. Vickery, L. N. Discenza, C. J. D'Arienzo, Y. Zhang, E. Heimrich, K. M Gillooly, T. L. Taylor, C. Pulicicchio, K. W. McIntyre, M. A. Galella, A. J. Tebben, J. K. Muckelbauer, C. Chang, R. Rampulla, A. Mathur, L. Salter-Cid, J. C. Barrish, P. H. Carter, A Fura, J. R. Burke, J. A. Tino, J. Med. Chem. 2016, 59, 9173-9200.

[9] For selected diastereoselective strategies to optically active multi-axis systems, see: a) T. Yanagi, K. Nogi, H. Yorimitsu, Synlett 2020, 31, 153-157; b) Q. Dherbassy, J.-P. Djukic, J. Wencel-Delord, F. Colobert, Angew. Chem. Int. Ed. 2018, 57, 4668-4672; Angew. Chem. 2018, 130, 4758-4762; c) G. Beutner, R. Carrasquillo, P. Geng, Y. Hsiao, E. C. Huang, J. Janey, K. Katipally, S. Kolotuchin, T. La Porte, A. Lee, P. Lobben, F. LoraGonzalez, B. Mack, B. Mudryk, Y. Qiu, X. Qian, A. Ramirez, T. M. Razler, T. Rosner, Z. Shi, E. Simmons, J. Stevens, J. Wang, C. Wei, S. R. Wisniewski, Y. Zhu, Org. Lett. 2018, 20, 37363740; d) K. Takaishi, M. Kawamoto, K. Tsubaki, Org. Lett. 2010 12, 1832-1835; e) K. Tsubaki, Org. Biomol. Chem. 2007, 5, $2179-2188$; f) N.-X. Hu, S. Xie, Z. Popovic, B. Ong, A.-M. Hor, J. Am. Chem. Soc. 1999, 121, 5097-5098.

[10] T. Hayashi, K. Hayashizaki, Y. Ito, Tetrahedron Lett. 1989, 30 , $215-218$.

[11] a) P. Loxq, E. Manoury, R. Poli, E. Deydier, A. Labande, Coord. Chem. Rev. 2016, 308, 131-190; b) D. Zhang, Q. Wang, Coord. Chem. Rev. 2015, 286, 1-16; c) M. C. Kozlowski, B. J. Morgan, E. C. Linton, Chem. Soc. Rev. 2009, 38, 3193-3207.

[12] a) A. M. Harned, Tetrahedron 2018, 74, 3797-3841; b) J. P. Vigneron, M. Dhaenens, A. Horeau, Tetrahedron 1973, 29. 1055-1059.

[13] D. Shen, Y. Xu, S.-L. Shi, J. Am. Chem. Soc. 2019, 141, $14938-$ 14945.

[14] Q.-H. Nguyen, S.-M. Guo, T. Royal, O. Baudoin, N. Cramer, J. Am. Chem. Soc. 2020, 142, 2161-2167.

[15] For reviews, see: a) A. Pla-Quintana, A. Roglans, Asian J. Org Chem. 2018, 7, 1706-1718; b) M. Amatore, C. Aubert, Eur. J. Org. Chem. 2015, 265-286; c) G. Domínguez, J. Pérez-Castells, Chem. Soc. Rev. 2011, 40, 3430-3444; For selected examples, see: d) N. Sakiyama, D. Hojo, K. Noguchi, K. Tanaka, Chem. Eur. J. 2011, 17, 1428-1432; e) G. Nishida, N. Suzuki, K Noguchi, K. Tanaka, Org. Lett. 2006, 8, 3489-3492; f) K. Tanaka, K. Takeishi, K. Noguchi, J. Am. Chem. Soc. 2006, 128, 4586-4587; g) A. Gutnov, B. Heller, C. Fischer, H.-J. Drexler, A. Spannenberg, B. Sundermann, C. Sundermann, Angew. Chem. Int. Ed. 2004, 43, 3795-3797; Angew. Chem. 2004, 116, 3883 3886.

[16] a) T. Shibata, T. Fujimoto, K. Yokota, K. Takagi, J. Am. Chem. Soc. 2004, 126, $8382-8383$; b) T. Shibata, Y. Arai, K. Takami, K. Tsuchikama, T. Fujimoto, S. Takebayashi, K. Takagi, Adv. Synth. Catal. 2006, 348, 2475-2483.

[17] T. Shibata, K. Tsuchikama, Chem. Commun. 2005, 6017-6019.

[18] K. Tanaka, T. Suda, K. Noguchi, M. Hirano, J. Org. Chem. 2007, $72,2243-2246$.

[19] T. Suda, K. Noguchi, M. Hirano, K. Tanaka, Chem. Eur. J. 2008, 14, 6593-6596.

[20] S. Ogaki, Y. Shibata, K. Noguchi, K. Tanaka, J. Org. Chem. 2011, 76, $1926-1929$.

[21] T. Shibata, K. Tsuchikama, M. Otsuka, Tetrahedron: Asymmetry 2006, 17, 614-619. 
[22] a) J. Oppenheimer, R. P. Hsung, R. Figueroa, W. L. Johnson, Org. Lett. 2007, 9, 3969-3972; b) J. Oppenheimer, W. L. Johnson, R. Figueroa, R. Hayashi, R. P. Hsung, Tetrahedron 2009, 65, 5001-5012.

[23] For a review, see: a) G. Ma, M. P. Sibi, Chem. Eur. J. 2015, 21, 11644 -11657; For selected examples, see: b) Y.-B. Wang, Q.-H. Wu, Z.-P. Zhou, S.-H. Xiang, C. Yuan, P. Yu, B. Tan, Angew. Chem. Int. Ed. 2019, 58, 13443-13447; Angew. Chem. 2019, 131 , 13577 - 13581; c) J. A. Carmona, V. Hornillos, P. Ramírez-López, A. Ros, J. Iglesias-Sigüenza, E. Gómez-Bengoa, R. Fernández, J. M. Lassaletta, J. Am. Chem. Soc. 2018, 140, 11067-11075 d) K. Mori, T. Itakura, T. Akiyama, Angew. Chem. Int. Ed. 2016 55, 11642-11646; Angew. Chem. 2016, 128, 11814-11818; e) J. Zheng, S.-L. You, Angew. Chem. Int. Ed. 2014, 53, 13244-13247; Angew. Chem. 2014, 126, 13460-13463; f) J. L. Gustafson, D. Lim, S. J. Miller, Science 2010, 328, 1251-1255; g) J. Clayden, S. P. Fletcher, J. J. W. McDouall, S. J. M. Rowbottom, J. Am. Chem. Soc. 2009, 131, 5331-5343.

[24] a) K. T. Barrett, S. J. Miller, J. Am. Chem. Soc. 2013, 135, 2963 2966; b) K. T. Barrett, A. J. Metrano, P. R. Rablen, S. J. Miller, Nature 2014, 509, 71-75.

[25] A. J. Fugard, A. S. K. Lahdenperä, J. S. J. Tan, A. Mekareeya, R. S. Paton, M. D. Smith, Angew. Chem. Int. Ed. 2019, 58, 2795 2798; Angew. Chem. 2019, 131, 2821-2824.

[26] For selected examples, see: a) X.-L. He, H.-R. Zhao, X. Song, B. Jiang, W. Du, Y.C. Chen, ACS Catal. 2019, 9, 4374-4381; b) S. Zhu, Y.-H. Chen, Y.-B. Wang, P. Yu, S.-Y. Li, S.-H. Xiang, J.-Q. Wang, J. Xiao, B. Tan, Nat. Commun. 2019, 10, 4268; c) A. Link, C. Sparr, Angew. Chem. Int. Ed. 2018, 57, 7136-7139; Angew. Chem. 2018, 130, 7254 - 7257; d) S. Maddox, G. A. Dawson, N. C. Rochester, A. B. Ayonon, C. E. Moore, A. L. Rheingold, J. L. Gustafson, ACS Catal. 2018, 8, 5443-5447; e) L. W. Oi, J.-H. Mao, J. Zhang, B. Tan, Nat. Chem. 2018, 10, 58-64; f) V. S. Raut, M. Jean, N. Vanthuyne, C. Roussel, T. Constantieux, C. Bressy, X. Bugaut, D. Bonne, J. Rodriguez, J. Am. Chem. Soc. 2017, 139, 2140-2143; g) O. Quinonero, M. Jean, N. Vanthuyne, C. Roussel, D. Bonne, T. Constantieux, C. Bressy, X. Bugaut, J. Rodriguez, Angew. Chem. Int. Ed. 2016, 55, 1401 -1405; Angew. Chem. 2016, 128, 1423-1427; h) J.-Z. Wang, J. Zhou, C. Xu, H. Sun, L. K"urti, Q.-L. Xu, J. Am. Chem. Soc. 2016, 138, 5202 5205 ; i) Y.-H. Chen, D.-J. Cheng, J. Zhang, Y. Wang, X.-Y. Liu, B. Tan, J. Am. Chem. Soc. 2015, 137, 15062-15065; j) G.-Q. Li, H. Gao, C. Keene, M. Devonas, D. H. Ess, L. K"urti, J. Am. Chem Soc. 2013, 135, 7414-7417; k) F. Guo, L. C. Konkol, R. J. Thomson, J. Am. Chem. Soc. 2011, 133, 18-20.

[27] a) A. I. Meyers, D. G. Wettlaufer, J. Am. Chem. Soc. 1984, 106 1135 -1136; b) J. A. Berson, E. Brown, J. Am. Chem. Soc. $\mathbf{1 9 5 5}$ 77, $450-453$.

[28] a) D. Lotter, M. Neuburger, M. l. Rickhaus, D. Häussinger, C. Sparr, Angew. Chem. Int. Ed. 2016, 55, 2920-2923; Angew. Chem. 2016, 128, 2973-2976; b) A. Link, C. Sparr, Angew.
Chem. Int. Ed. 2014, 53, 5458-5461; Angew. Chem. 2014, 126 , 5562-5565.

[29] D. Lotter, A. Castrogiovanni, M. Neuburger, C. Sparr, ACS Cent. Sci. 2018, 4, 656-660.

[30] For selected reviews, see: a) I. P. Beletskaya, C. Nájera, M. Yus, Chem. Rev. 2018, 118, 5080-5200; b) M. Bihani, J. C.-G. Zhao, Adv. Synth. Catal. 2017, 359, 534-575; c) L. Lin, X. Feng, Chem. Eur. J. 2017, 23, 6464-6482.

[31] A. Castrogiovanni, P. Herr, C. B. Larsen, X. Guo, C. Sparr, O. S Wenger, Chem. Eur. J. 2019, 25, 16748-16754.

[32] a) Y.-L. Hu, Z. Wang, H. Yang, J. Chen, Z.-B. Wu, Y. Lei, L. Zhou, Chem. Sci. 2019, 10, 6777-6784; b) For one isolated example of a bis-axially chiral 2,3-diarylbenzoindole with a low enantiomerization barrier around the indole C3-aryl axis, see: Y.-P. He, H. Wu, Q. Wang, J. Zhu, Angew. Chem. Int. Ed. 2020, 59, 2105-2109; Angew. Chem. 2020, 132, 2121-2125.

[33] X. Bao, J. Rodriguez, D. Bonne, Chem. Sci. 2020, 11, 403-408.

[34] G. D. Bisag, D. Pecorari, A. Mazzanti, L. Bernardi, M. Fochi, G. Bencivenni, G. Bertuzzi, V. Corti, Chem. Eur. J. 2019, 25, 1569415701.

[35] W. Xia, Q.-J. An, S.-H. Xiang, S. Li, Y.-B. Wang, B. Tan, Angew. Chem. Int. Ed. 2020, https://doi.org/10.1002/anie.202000585; Angew. Chem. 2020, https://doi.org/10.1002/ange.202000585.

[36] L.-W. Qi, S. Li, S.-H. Xiang, J. Wang, B. Tan, Nat. Catal. 2019, 2 , 314-323.

[37] a) F. Doria, C. Percivalle, M. Freccero, J. Org. Chem. 2012, 77 3615-3619; b) M. Furusawa, K. Arita, T. Imahori, K. Igawa, K. Tomooka, R. Irie, Tetrahedron Lett. 2013, 54, 7107-7110.

[38] For a recent highlight, see: J. Rodriguez, D. Bonne, Chem Commun. 2019, 55, 11168-11170.

[39] a) S. Jia, Z. Chen, N. Zhang, Y. Tan, Y. Liu, J. Deng, H. Yan, J. Am. Chem. Soc. 2018, 140, 7056-7060; b) S. Li, D. Xu, F. Hu, D. Li, W. Qin, H. Yan, Org. Lett. 2018, 20, 7665-7669; c) Y. Liu, X. Wu, S. Li, L. Xue, C. Shan, Z. Zhao, H. Yan, Angew. Chem. Int Ed. 2018, 57, 6491-6495; Angew. Chem. 2018, 130, 6601-6605; d) Y. Tan, S. Jia, F. Hu, Y. Liu, L. Peng, D. Li, H. Yan, J. Am Chem. Soc. 2018, 140, 16893-16898; e) A. Huang, L. Zhang, D. Li, Y. Liu, H. Yan, W. Li, Org. Lett. 2019, 21, 95 -99; f) L. Peng, K. Li, C. Xie, S. Li, D. Xu, W. Qin, H. Yan, Angew. Chem. Int. Ed. 2019, 58, 17199-17204; Angew. Chem. 2019, 131, 17359-17364 g) S. Jia, S. Li, Y. Liu, W. Qin, H. Yan, Angew. Chem. Int. Ed. 2019, 58, 18496-18501; Angew. Chem. 2019, 131, 18667-18672.

[40] a) H. Takano, N. Shiozawa, Y. Imai, K. S. Kanyiva, T. Shibata, J. Am. Chem. Soc. 2020, 142, 4714-4722; b) T. Shibata, G. Nishizawa, K. Endo, Synlett 2008, 765-768. 